\title{
Un tránsito de la sangre al plástico: lo prostético en las representaciones del deseo de maternidad de Frida Kahlo
}

\author{
TATIANA ROJAS PONCE Universidad Simón Bolívar, Venezuela \\ ORCID 0000-0002-4343-0575 \\ tatianitat@gmail.com
}

\section{Resumen}

Yo y mi muñeca (1937) de Frida Kahlo es un cuadro que permite problematizar el relato del dolor por la imposibilidad de ser madre que se ha petrificado en torno a la figura de la popular pintora mexicana. En él, Kahlo habla del aborto sin aludirlo y sin asociarlo a ningún signo de padecimiento, componiendo una representación compleja y enigmática de lo materno, que contrasta con otros momentos más conocidos de su obra. En la primera parte de este artículo, me concentro en el análisis del lienzo en comparación a otras pinturas, enfatizando su carácter disruptivo, y el modo en que se aleja del discurso nacionalista sobre la maternidad, para acercarse a una estética ciborg menos programática. En la segunda parte tomo las consideraciones de P.B. Preciado sobre el dildo para extrapolarlas a la muñeca, postulando que ambos son objetos suplementarios (en el sentido derridiano del término) que imitan al mismo tiempo que denuncian la falsedad de lo imitado. Este recurso teórico me permite aproximarme a lo que hay de prostético en la representación del deseo de maternidad de Frida Kahlo.
Palabras clave: Frida Kahlo / maternidad / muñeca / ciborg / suplemento / dildo / contrasexualidad / prostético

\section{A passage from blood to plastic: prosthetics in representations of Frida Khalo's motherhood desire}

Abstract

Frida Kahlo's Me and My Doll (1937) is a painting that allows to problematize the petrified narrative of pain due to the impossibility of being a mother that has been built around the figure of the popular Mexican painter. In the painting, Kahlo talks about abortion without alluding to it and without associating it with any signs of suffering, composing a complex and enigmatic representation of the maternal, which contrasts with other more well-known moments of her work. In the first part of this article, I focus on analyzing the canvas in comparison to other paintings, emphasizing its disruptive nature, and the way it diverges from the nationalistic discourse on motherhood, to approach a less programmatic cyborg aesthetic. In the second part I take the

Recibido: 11/6/2020. Aceptado: 29/8/2020

Para citar este artículo: Rojas Ponce, T. (2020). Un tránsito de la sangre al plástico: lo prostético en las representaciones del deseo de maternidad de Frida Kahlo. El taco en la brea, 12 (junio-noviembre). Santa Fe, Argentina: UNL. eoo16 DOI: 10.14409/tb.v1i12.9694 
considerations of P.B. Precious on the dildo to extrapolate them to the doll, postulating that they both are supplementary objects (in the Derridian sense of the term), objects which imitate while denouncing the falsity of what is imitated. This theoretical resource allows me to examine the prosthetics features in the representation of Frida Kahlo's desire for motherhood.

Key words: Frida Kahlo / motherhood / doll / cyborg / supplement / dildo / contrasexuality / prosthetics

\section{I.}

Hay un cuadro de Frida Kahlo del que no se ha dicho tanto: Yo y mi muñeca (1937). En él, Frida se pinta en el centro de un cuarto sentada y erguida sobre un austero catre. Su atuendo es también austero, tradicional pero sin collares ni adornos, ni flores en el cabello apenas recogido por un simple lazo negro. Es un atuendo más bien casero. Las manos cruzadas sobre el regazo. En la derecha sostiene un cigarrillo. A su lado izquierdo (siniestro), también sentada, reposa una muñeca desnuda y blanquecina, con algunos tonos rosas que caricaturizan su ternura, y otros trazos grises que resaltan su carácter inanimado, un poco mortífero. La muñeca resulta aún más blanca por la contigüidad con la figura de Frida, esta vez representada con un color de tez curiosamente más oscuro que el establecido en su propia norma de autorretratos sistemáticos. Por esa austeridad del atuendo y por la del cuarto en el que se inscribe la imagen: despoblado, desposeído, sin más que un catre sobre el piso de terracota y la pared vacía; y también por esa diferencia racial de la blanca muñeca con la Frida india, parecería que estamos ante el cuarto de una Frida sirvienta o nana de esta inquietante muñeca. Pero hay una peculiaridad en ambas figuras, que más bien las afilia en una relación maternal imposible o absurda, y consiste en que el rostro de la muñeca está, al igual que el de Frida, rasgado por las mismas cejas amplias y negras, que parecen indicar una especie de herencia. Hay en este cuadro una representación compleja y enigmática de la maternidad, que contrasta con otros momentos más conocidos de su obra, e incluso permite revisar desde otra perspectiva toda la mitología que envuelve el supuesto padecimiento de la artista mexicana por los sucesivos abortos que atraviesan la historia de su enfermedad. Es un cuadro carente de adjetivaciones, casi desprovisto de simbologías, en el que lo único orgánico es la imagen de sí misma, y en el que, a diferencia de los cuadros de 1932, Kahlo habla del aborto sin aludirlo, y sin asociarlo a ningún signo de dolor. Ella se muestra vestida, entera, sin una gota de sangre que manche la cama o fertilice la tierra. Pero la herida allí ausente, u oculta, quizás solo haya cambiado de forma y se haya desplazado fuera del cuerpo, fijándose en este objeto peculiar que es la muñeca. Es un cuadro raro dentro del inmenso conjunto de cuadros que pintó Frida Kahlo, que sin embargo dialoga en muchos sentidos con otros.

Por ejemplo, y solo para mencionar dos de las posibles conexiones, Yo y mi muñeca por una parte remite al Autorretrato en la frontera (1932) y por otro lado a Las dos Fridas (1939). En ambos casos Frida pinta duplicidades y divisiones que problematizan el tema de la identidad en varios niveles. En el Autorretrato en la frontera la dualidad está en el paisaje. A la derecha de Frida, se despliega un México mítico y prehispánico en ruinas pero fértil, en el que sobreviven las representaciones de los dioses, aflora una vegetación exuberante y el sol y la luna tienen rostro. Un paisaje que, a pesar de estar repleto de elementos, guarda espacios desérticos, como vacíos donde hubiera un llamado para la creación de aquello aún por hacer. En contraste, a su lado izquierdo 
las máquinas y chimeneas de las industrias y rascacielos de Detroit contaminan casi todos los rincones, rodeando de humo la bandera estadounidense y dejando apenas resquicios de tierra despoblada entre los tubos metálicos, como si de ese lado estuviera todo hecho y no hubiera ni lugar para lo nuevo, ni espacio para la tradición, representada del lado mexicano por las ruinas de la civilización azteca y sus deidades. El lado norte es un espacio bien calculado de elementos simétricos, que no se deja permear por lo azaroso de la vida silvestre. En la parte inferior del cuadro, los cables eléctricos del norte conectados con las raíces de la vegetación en el sur, podrían indicar una crítica al extractivismo, y a la relación de interdependencia y causalidad entre ambos sistemas: la expresión de que el desarrollo industrial del lado norte solo es posible con la energía de los recursos naturales del lado sur. Frida se pinta en el medio de estos dos mundos distintos. Ese borde entre el norte y el sur, entre un estadio y otro de la modernidad, es también el límite entre lo estéril y lo fértil. Ese límite es ella misma. En el cuadro Frida no solo está en la frontera, ella es la frontera.

El tópico se repite con variaciones en Las dos fridas (1939), en el que Kahlo se duplica sobre el fondo uniforme de un cielo nublado y nocturno. La Frida de la derecha está con un vestido de tehuana igual al de Yo y mi muñeca (1937), mientras que la de la izquierda lleva un traje blanco más moderno, otra vez expresando la oposición de dos maneras de experimentar la identidad en el marco de las tensiones geopolíticas entre México y Occidente. Las dos Fridas están tomadas de la mano, sentadas sobre un mueble muy similar al catre de Yo y mi muñeca (1937). A cada una le cuelga un corazón al aire por fuera de
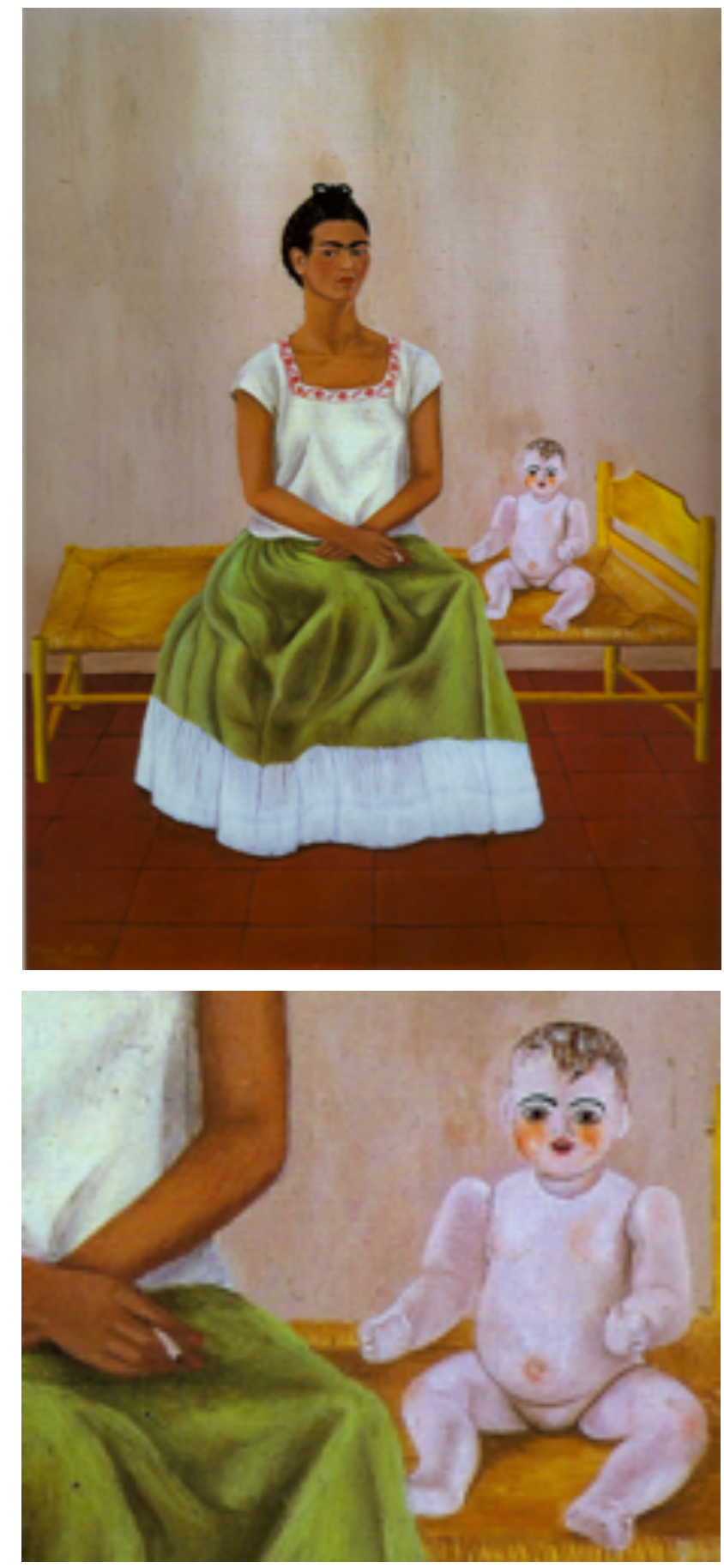
la ropa, y estos órganos gemelos están conectados por unas venas también externas que rodean sutilmente las dos figuras. El corazón y el vestido de la Frida occidental están rotos, y el hecho de que esta sostenga una tijera en la mano, supone la autoflagelación. La tijera ha cortado la vena conectora que establece el continuum entre ambas Fridas, manchando de rojo el vestido occidental blanco, con lo cual queda implicado que por ese corte fluirá la sangre de las dos. Este elemento quirúrgico en su mano, podría significar la toma del poder de intervención autónoma sobre el cuerpo propio, tan repetidamente intervenido por el Otro de la medicina: el accidente, las operaciones, los abortos. La Frida tehuana, en cambio, sostiene un pequeño camafeo con el retrato de Diego Rivera niño. La tijera y el camafeo están en relación de oposición especular. La Frida tehuana de corazón expuesto pero entero se aferra a un 

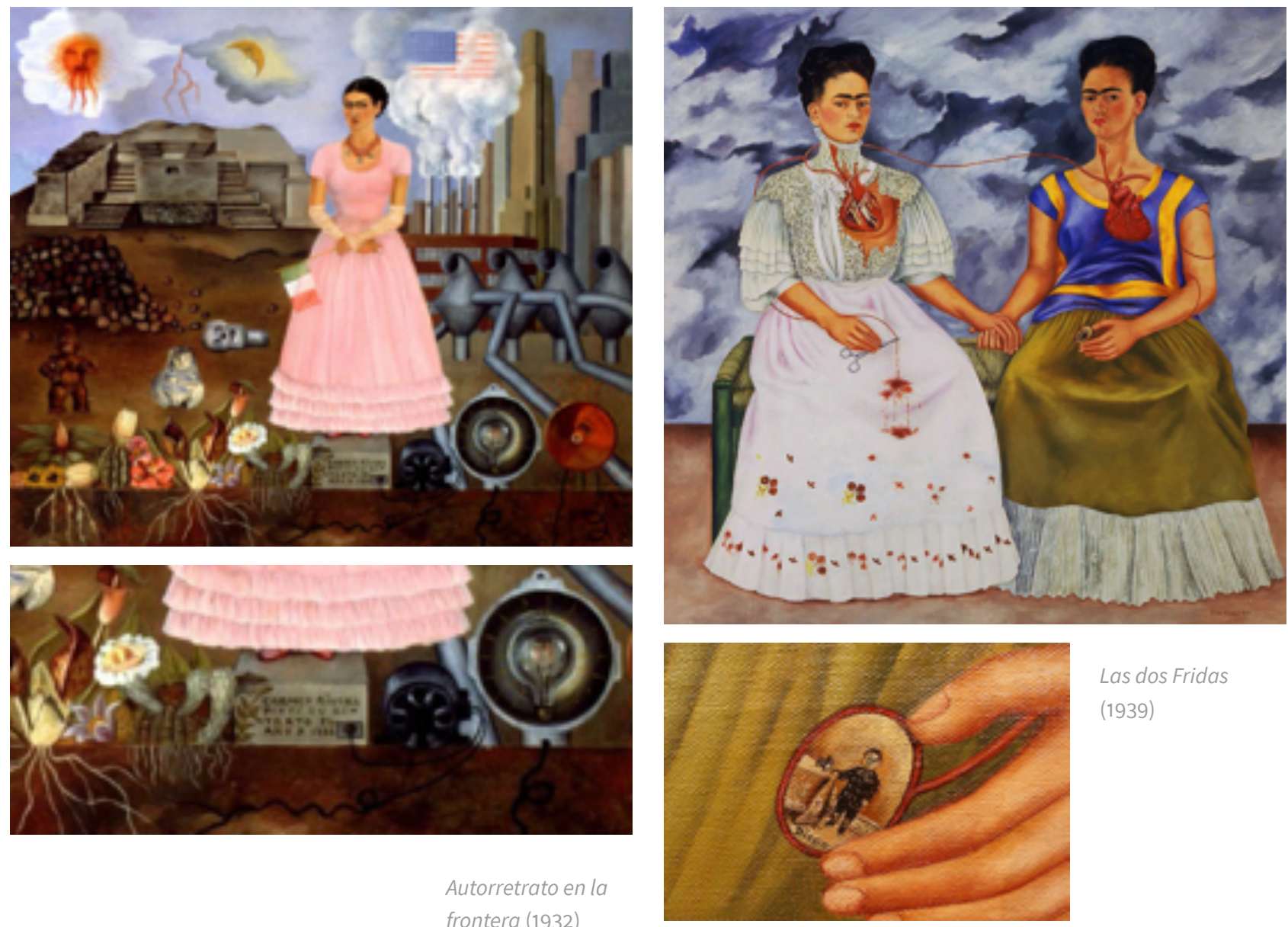

Las dos Fridas

(1939)

Autorretrato en la

frontera (1932)

dispositivo de la memoria enmarcado en las lógicas de representación y reproducción del amor y la familia, mientras que la otra Frida rota hace uso de un utensilio quirúrgico sobre sí misma. Ambos elementos, pertenecientes a los universos de la institución médica y la institución familiar, son puestos aquí en relación con la experiencia de la identidad doble y el consecuente desangramiento de la mujer entonces dividida e incapaz de imaginarse como «una».

Yo y mi muñeca (1937) hace serie con estos dos cuadros, porque en los tres está presente la oposición de elementos en el eje horizontal, que marca una fractura identitaria; pero aquí la oposición de las figuras no es simétrica. Hay una Frida adulta al lado de una muñeca que es la imitación absurda de la bebé que le falta, con la que no juega y a la que ni siquiera mira. La contigüidad expresa cierta posición maternal, pero no hay contacto. Frida sostiene en su mano un cigarrillo que la previene de interactuar con esa no-hija que es la muñeca. Exhibe así el goce privado y autoerótico de la mujer que fuma con el aplomo de quien sabe — solo ella — la «nada» radical que esa muñeca representa en el lienzo. Madre imposible, madre nociva, madre india de una mercancía blanca, madre otra, madre frontera.

Más por contraste que por analogía, esta maternidad imposible de una hija ausente, me permite señalar también la relación que se produce entre Yo y mi muñeca y el cuadro El abrazo de amor del universo, la Tierra (México), Diego, Yo y el Sr. Xolotl (1949). El abrazo... es uno de los cuadros más conocidos de Frida, reproducido por millones por el Estado mexicano en el reverso del 
billete de quinientos pesos, y por lo tanto consagrado como emblema de lo nacional. En esta hilera de cuerpos que se abrazan unos a otros, las relaciones maternales se multiplican de manera descendente y teleológica en el eje vertical. Se trata de una cosmogonía que va de lo celestial a lo terrenal, en la que (una sola) Frida parece representar alegóricamente a México. Aquí también Frida es una frontera, no ya geopolítica sino cronológica, un límite entre lo mítico y lo histórico que funda la mexicanidad. Situada en ese borde, pinta su cuerpo maternalmente dispuesto en función de sostener el cuerpo desnudo de un Diego Rivera híbrido (también fronterizo) en tanto aparece como adulto en posición de niño, con un tercer ojo en la frente, quizás un símbolo del hombre nuevo llamado a hacer la revolución.

A diferencia de Yo y mi muñeca, El abrazo... es una de las obras en las que Khalo resuelve armónicamente la representación de su maternidad, dándole un lugar preciso en este relato nacionalista: la madre del hombre nuevo que dona su cuerpo - y su imagen — de manera sacrificial a la patria y a la historia. Allí la maternidad, sí es posible. Madre heroína, madre revolucionaria, madre ideología. Como afirma Nuria Girona al respecto, en Frida:

\begin{abstract}
La ofrenda de la imagen adquiere visos de sacrificio y en esta renuncia, el cuerpo descarnado cede para revestirse de otros relatos (cuerpo de la patria, cuerpo de Rivera, cuerpo de su vida). (...) En esta cesión insisto: complaciente, autorizada, estratégica se abonarán las sucesivas interpretaciones, apropiaciones y versiones a las que ha dado lugar su figura, que se disparan en dos direcciones precisas: las lecturas críticas que restringirán el signo-Kahlo a un cuerpo trizado y enamorado (persiguiendo un determinismo que aminore sus gestos desestabilizadores) y las que posteriormente la elevarán como ícono mexicano. Ambas comportan operaciones de vaciado y modelado de su silueta, de desvelamiento y ocultación, en las que ella misma se generő. (202)
\end{abstract}

Inscrito en esa mitología revolucionaria, el gesto teleológico de donar la imagen propia, se parece al deseo de la maternidad que no ocurrió. El deseo de ser madre y el de ofrecer la imagen de sí a la mirada pública tienen en común una marcada pulsión por legar(se) que, como han señalado autoras como Nuria Girona y Eleonora Cróquer, es una operación en la que Khalo misma prefigura y propicia el uso frenético que posteriormente se ha hecho de su imagen, y su ascenso al estatuto de ícono para diversos fines que van del nacionalismo a la industria del entretenimiento, pasando por ejemplo por los movimientos feministas.

El abrazo... participa de una construcción iconográfica de lo nacional enmarcada en una concepción del progreso lineal de la historia, muy propia de la época, según la cual mientras los hombres son llamados a la heroicidad, a consagrar sus acciones y obras a la patria, las mujeres son llamadas a ser las paridoras de estos héroes. Ambos, madres y héroes, convocados así al servicio de

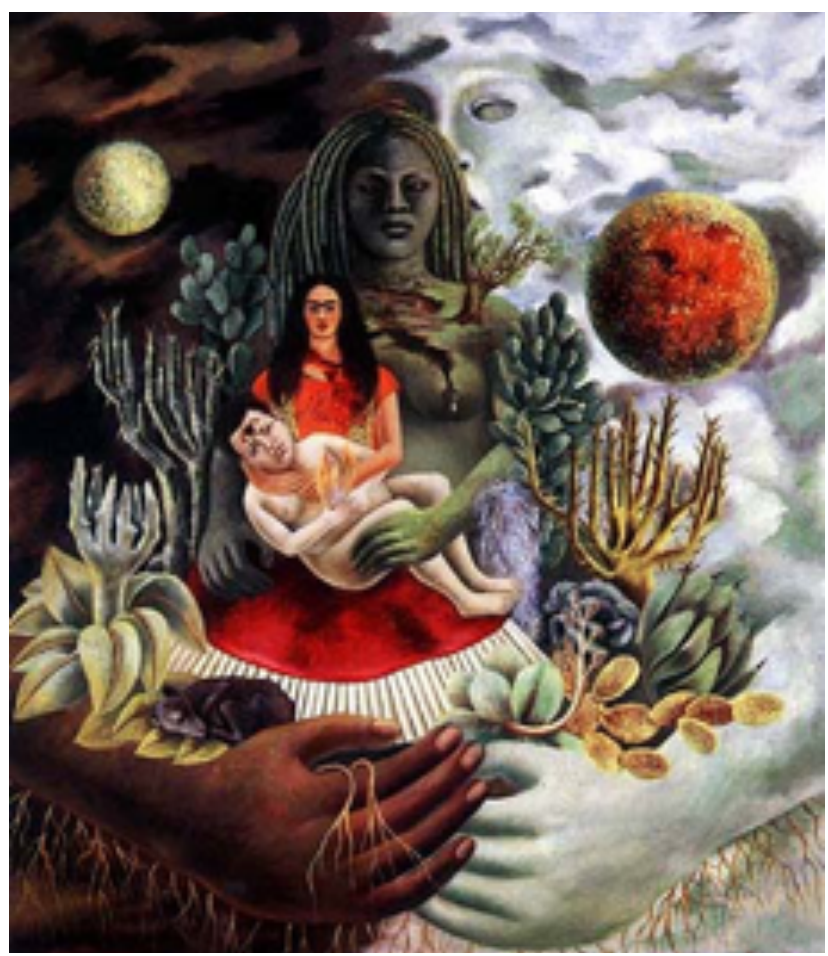

Las dos Fridas (1939) 
la edificación del futuro y la identidad nacional. Por el contrario, Yo y mi muñeca plantea una ruptura con esta narrativa y su programa político. Habla de otra cosa más enigmática que programática. Lo que dice este cuadro sobre la maternidad es difícil de restringir en el melodrama biográfico de «cuerpo trizado y enamorado» que enfatiza el papel de madre frustrada de la pintora mexicana. Y, aun cuando una de sus principales biógrafas e impulsoras de este relato, Hayden Herrera, reseña de pasada la afición de Khalo por coleccionar muñecas como una consecuencia lineal de sus abortos, el discurso oficial sobre ella no se detiene en este cuadro, ni se le ha dado mayor importancia al dato. Así, la biógrafa se refiere al lienzo de la siguiente manera:

La pena de Frida al no poder ser madre se expresó tanto directa como indirectamente. En Yo y mi muñeca, pintado en 1937 cuando Frida tal vez tuvo otro aborto, adoptó el tema convencional de la madre y el niño y le extrajo su retórica usual (...). Mira directamente hacia nosotros, no a su «bebé». Sus manos están cruzadas sobre su regazo y como en completo desafío al sentimiento, fuma. (1997:75)

Para Herrera, el interés de Khalo por los animales e incluso por las plantas, se explica también desde esta pena de la madre frustrada.

\begin{abstract}
Además de sus muñecas, Frida encontró otros sustitutos para reemplazar sus hijos propios. Tenía a los dos niños de su hermana Cristina, quienes la trataban como una segunda madre (...). No contenta con eso, había reunido una colección de animales en su casa de Coyoacán (...). La infertilidad de Frida provocó una urgencia en cuanto a sus relaciones con todo tipo de formas de vida. Nutría a las plantas de su jardín como si fueran hijos propios. (78)
\end{abstract}

Herrera pareciera haber abonado el terreno para que «este hiperconnotado compuesto de vida y obra que conocemos como Frida Kahlo» (Cróquer:25) esté plagado de interpretaciones petrificadas, difíciles de desprogramar, que hacen pasar todos los aspectos de su trabajo y anécdotas de su biografía por el dolor de la falta de hijos, el accidente, la enfermedad o la relación con Diego Rivera. Los ejemplos son numerosos, y van desde las múltiples semblanzas de la pintora, que proliferan en historias del arte o monografías especializadas, hasta grandes producciones cinematográficas, como la Frida protagonizada por Salma Hayek en 2002, pasando por otras representaciones documentales o literarias. Por citar un caso relativamente reciente, en la obra teatral Viva la vida del mexicano Humberto Robles (1998), presentada en Caracas en 2014, el autor pone estas palabras en la boca del personaje de Frida: «Pero una tarde a mis amigas de la escuela les dije: "Van a ver... un día voy a tener un hijo de Diego Rivera..." (Pausa). He tenido abortos y a cada uno lo he enterrado... Perdí tres hijos y otra serie de cosas que hubieran podido llenar mi horrible vida» (Robles).

En el recorte de este relato petrificado que podríamos llamar la doxa que circula sobre Frida Khalo, importa y significa tanto lo que se incluye como lo que queda afuera. De tal modo, en el museo de La Casa Azul, se encuentra conservada la colección de figurillas provenientes de culturas indígenas que la pareja Rivera-Khalo atesoró; y hace unos años una exposición de los vestidos de Khalo dio la vuelta al mundo levantando una intensa cobertura mediática. Pero en cambio esta colección de muñecas, apenas mencionada por Herrera, no fue preservada, curada o exhibida con el mismo interés. Quizá porque, como sabemos, el relato de la Historia no solo 
invisibiliza subjetividades y discursos que ponen en cuestión la aparente homogeneidad de las generalizaciones que lo sostienen, sino que también se esfuerza en sostener las interpretaciones tendentes a capturar la potencia perturbadora del discurso que algunas subjetividades inscriben a veces escandalosamente en la cultura.

En Rituales de la verdad, Nuria Girona señala en una nota al pie la relación de la mencionada colección de objetos indígenas (legitimada por la tradición) y el uso que la cultura ha hecho de la propia imagen de Khalo:

Baste pensar en la «colección» de objetos precolombinos que la pareja atesoró y las implicaciones de este melancólico gesto, que como planteaba anteriormente, trastoca el «objeto natural» (antropológico) en objeto artístico y decorativo. Una parte del destino de la figura de Kahlo corre parejo a esta colección como una pieza más; no deja de ser, como detallaré más adelante, que ella misma termina personificando esta ficción etnográfica. (205)

Otra parte de su destino quizás haya corrido en paralelo al gesto disruptivo que despunta en Yo y mi muñeca, que no solo establece un corte sobre el relato del sufrimiento asociado a la maternidad imposible de la pintora, sino que se inscribe en otro telos, al alejarse de lo edificante del discurso nacional para acercarse a una estética ciborg más apocalíptica o distópica (Haraway), en la que lo humano se afilia maternalmente con un objeto inorgánico resultante de la producción industrial taylorizada, en pleno auge del fordismo.

\section{II.}

En su libro Máquinas de amar. Secretos del cuerpo artificial, Pilar Pedraza analiza la proximidad de la mujer con lo inorgánico en múltiples representaciones construidas desde una mirada masculina a lo largo de la historia de la cultura en Occidente. Desde el mito de Pigmaleón hasta el cine actual, las estatuas, las autómatas, e incluso los cadáveres femeninos, han sido el objeto de fantasías y fetichismos y han alimentado viejos complejos culturales, según los cuales, por un lado, los hombres son capaces de fabricar mujeres artificiales más bellas, más virtuosas, más limpias y más convenientes que las mujeres reales; y, por otro, la mujer es una cosa o mercancía que puede ser consumida y desechada. La muñeca de uso infantil se inscribe en esta tradición misógina (aunque no se agote del todo en ella). La muñeca es una hija-cosa para la niña no-madre, y al mismo tiempo le enseña a ser cosa a ella misma, ya que tiende a identificarse con ese objeto y su artificialidad.

Una muñeca funciona como un pequeño alter ego de plástico dispuesto para la proyección. A través de ella, malestares y deseos de otra forma inconfesables encuentran un canal de expresión. A la muñeca le duele su pierna cuando la niña se cae. La muñeca merece ser castigada cuando la niña cometió alguna falta. Una muñeca reproduce y representa el vínculo invertido de la niña con su madre. Es también, por ende, un dispositivo de su identificación con ella. Para decirlo de una vez: una muñeca es un dispositivo de género, un instrumento destinado a delinear la propia vocación femenina y maternal de las niñas. La muñeca es anterior al deseo del hijo, es un objeto que el mundo nos ofrece para fundar ese deseo, que nace entonces plastificado e inorgánico en sus inicios.

Una muñeca: la imitación plástica de una hija, la imagen de la hija fetichizada, una prótesis para cubrir la pérdida, o para suplir la incapacidad de parir del cuerpo femenino infantil, un 
entrenamiento para su futuro destino ineludiblemente materno. Una muñeca articula estas tres operaciones de proyección, identificación y adición prostética, no de una parte, sino del todo de un cuerpo-hijo que no ha sido, no ha podido ser, no fue, o no será.

P.B. Preciado en Manifiesto contrasexual presenta un planteamiento que revoluciona los estudios de género y la teoría queer, a partir de la genealogía de un objeto aparentemente irrelevante y anecdótico como el «dildo», con el cual encuentro que la muñeca guarda un parentesco singular. Para Preciado, el dildo es mucho más que un juguete sexual. O dicho de otra manera, los juguetes sexuales merecen un análisis exhaustivo y particular en tanto son objetos que determinan y estructuran prácticas e identidades; y en tanto son parte de una tecnología biopolítica que regula, controla y prefigura una relación específica entre los cuerpos de los usuarios y los artefactos de los que disponen para satisfacerse:

La «historia de la humanidad», saldría beneficiada al rebautizarse como «historia de las tecnologías», siendo el sexo y el género aparatos inscritos en un sistema tecnológico complejo. Esta «historia de las tecnologías», muestra que «La Naturaleza Humana», no es sino un efecto de negociación permanente de las fronteras entre humano y animal, cuerpo y máquina (Donna Haraway, 1995), pero también entre órgano y plástico.

(...)

Es necesario establecer conexiones políticas y teóricas entre el estudio de los aparatos y los artefactos sexuales (tratados hasta aquí como anécdotas de poco interés dentro de la historia de las tecnologías modernas) y los estudios sociopolíticos del sistema sexo/género. (Preciado:15-16)

La muñeca bebé, sin ser un juguete sexual, está hecha de su misma sustancia. Comparte con el dildo no solo las condiciones de posibilidad material de su fabricación, sino también el mismo principio de la mímesis del cuerpo humano: entero para el consumo fálico, recortado para el consumo femenino. Una muñeca es un juguete de género. Todos los juguetes lo son un poco, pero la muñeca lo es por excelencia, en tanto es un dispositivo para niñas. Jugar con muñecas y alcanzar un estadio en el que se deja de hacerlo determina incluso el umbral que un sujeto debe atravesar para dejar de ser niña. Al igual que el dildo, la muñeca es un objeto resultante de la operación de extraer, cosificar y plastificar aquello del cuerpo que determina la diferencia sexual: en el cuerpo femenino la capacidad de parir un cuerpo-hijo y en el cuerpo masculino la fantasía de tener un pene. Curiosamente se emparentan así dos objetos destinados a dos tipos de juegos aparentemente incompatibles.

El hecho de haber «extraído del cuerpo», en forma de dildo, el órgano que instituye el cuerpo como «naturalmente masculino", debe considerarse como un acto estructural e histórico decisivo entre los procesos de deconstrucción de la heterosexualidad como naturaleza. (...) El dildo no es sólo un objeto sino que es, estructuralmente, una operación de cortar-pegar: una operación de desplazamiento del supuesto centro orgánico de producción sexual hacia un lugar externo del cuerpo (...). El dildo puede ser considerado un ejemplo paradigmático de lo que Derrida definió como «el peligroso suplemento» en su análisis de la oposición naturaleza/cultura en Rousseau «el suplemento suple. No añade más que para reemplazar. Invierte o se insinúa en-lugar-de; si colma es como se colma un vacío. Si representa y da una imagen, es por falta anterior de una presencia. Suplente y vicario, el suplemento es un adjunto, una instancia 
subalterna que hace-las-veces-de. En tanto que sustituto, no se añade simplemente a la positividad de una presencia, no produce ningún relieve, su sitio está asignado en la estructura por la marca de un vacío. En algún lugar algo no puede llenarse consigo mismo, no puede realizarse más que dejándose colmar por signo y procuración». (Derrida, De la gramatología citado por Preciado: 68-69)

La muñeca también es, en el sentido derridiano del término, un ejemplo paradigmático de suplemento, en tanto que «produce aquello que supuestamente debe completar» (Preciado:14); esto es, en este caso, tanto el deseo de maternar como el cuerpo-hijo que no está. Si el dildo es un intermediario entre el falo y el pene, la muñeca viene a ocupar un lugar estratégico entre el ideal del hijo y el real del hijo. Muñeca y dildo comparten la particularidad de ser centros de significación diferidos. Para Frida, ese real es el aborto, la muerte y expulsión de la materia de ese cuerpo-hijo inacabado. La muñeca entonces es obturadora de dos faltas que no colma: la del deseo inicial de ser madre y la del cuerpo-hijo perdido. Precisamente un objeto suplementario que imita al mismo tiempo que denuncia la falsedad de lo imitado.

Mientras que el fetiche freudiano sustituye, por desviación de la mirada de un objeto original, el suplemento derridiano desplaza al tiempo que denuncia aquello desplazado. Al fetichizar se desplaza la mirada, pero no el objeto. El objeto permanece en la ecuación en negativo, mientras que el suplemento, al desplazar, se carga de una positividad. La muñeca es la admisión de que no hay hijo y la escena ridiculiza su ausencia, no está allí para sustituir al hijo sino para demostrar abiertamente su falta. Yo y mi muñeca (1937) es lo que P.B. Preciado podría llamar una representación contrasexual de lo materno, en tanto que propone una contra-productividad, una forma de placer-saber —o de goce a partir del saber - alternativo a la norma prescrita de la maternidad o al duelo por la imposibilidad de su realización.

El nombre de contra-sexualidad proviene indirectamente de Foucault, para quien la forma más eficaz de resistencia a la producción disciplinaria de la sexualidad en nuestras sociedades liberales no es la lucha contra la prohibición (como la propuesta por los movimientos de liberación sexual anti-represivos de los años setenta), sino la contra-productividad, es decir, la producción de formas de placer-saber alternativas a la sexualidad moderna. Las prácticas contra-sexuales que van a proponerse aquí deben comprenderse como tecnologías de resistencia, dicho de otra manera, como formas de contra disciplina sexual. (19)

Para Preciado, el dildo instaura una sexualidad propositiva y una contra-disciplina, mientras que para Freud el fetiche es el objeto de una sexualidad desviada (Assoun:77 y ss.). Sin embargo, el dildo y el fetiche comparten la condición de mercancía; y, más allá de los juicios y valoraciones decimonónicas, ambas categorías plantean una teoría de aproximación a la relación eróticaafectiva o libidinal con lo inorgánico.

Giorgio Agamben, en un pasaje de su libro Estancias, apunta las distintas transformaciones del concepto de fetichismo resaltando la contraposición entre los usos normales y anormales de los objetos, establecidos por un sistema de reglas represivas de la cultura: 
trata de la transferencia de un objeto material a la esfera de impalpable de lo divino, para Marx, de la violación del valor de uso; para Binet y Freud, de la desviación del deseo propio. El mapa de las migraciones del concepto de fetichismo dibuja así en filigrana el sistema de las reglas que codifican un género de represión del que los teóricos de la liberación no se han ocupado todavía: la que se ejerce sobre los objetos fijando sus normas de uso. Este sistema de reglas es, en nuestra cultura, tan rígido, aunque aparentemente no sancionado, que, como lo muestra el ready-made, la simple transferencia de un objeto de una esfera a otra basta para hacerlo irreconocible e inquietante. Pero existen objetos que están desde siempre destinados a un uso tan particular, que puede decirse que se sustraen en realidad a toda regla de uso. Se trata de los juguetes. (108)

Sin embargo hay prescripciones claras para el uso de una muñeca, y una mujer que ha atravesado el umbral hacia la adultez ya no está autorizada para el juego con ella. En la proximidad a la muñeca, Frida suplanta la identidad de la hija-niña no nacida que le falta y regresa siniestramente a su propia niñez. La muñeca es siniestra en el sentido freudiano no solo porque desestabiliza la distinción entre lo animado y lo inanimado, sino porque a la vez comporta la regresión de una etapa arcaica superada.

Este uso de la muñeca como prótesis mortuoria podría ser un antecedente a la aparición de los reborns dolls, una selecta curiosidad de la era posfordista, varias décadas más tarde. Los rebor$n s$ son representaciones de bebés extra realistas, fabricados a través de un complejo y costoso proceso artesanal, que circulan en un reducido pero consecuente mercado de internautas desde finales de la década de los noventa y principios de los dosmiles. Entre sus usos más frecuentes, se encuentra el de estructurar una fantasía negadora de la muerte, suplementando la falta de las madres que han perdido un hijo, o un embarazo. También son comprados por meros coleccionistas, y consumidos por mujeres que, por imposibilidad o conveniencia, buscan generar una práctica lo más mimética posible de la maternidad, desprovista del intercambio de fluidos y del riesgo de poner en juego la vida que ella trae consigo.

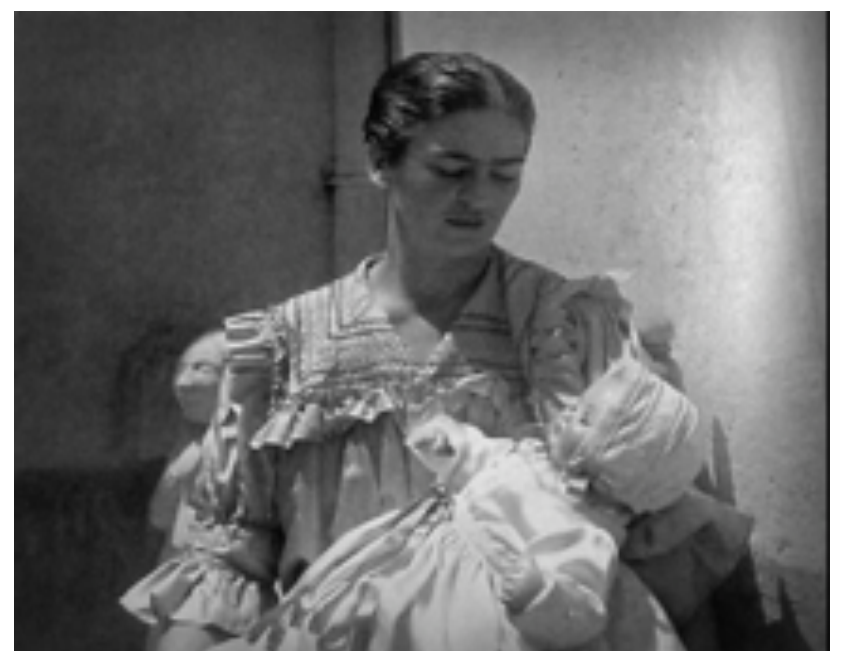

Frida Kahlo (autory año desconocidos)

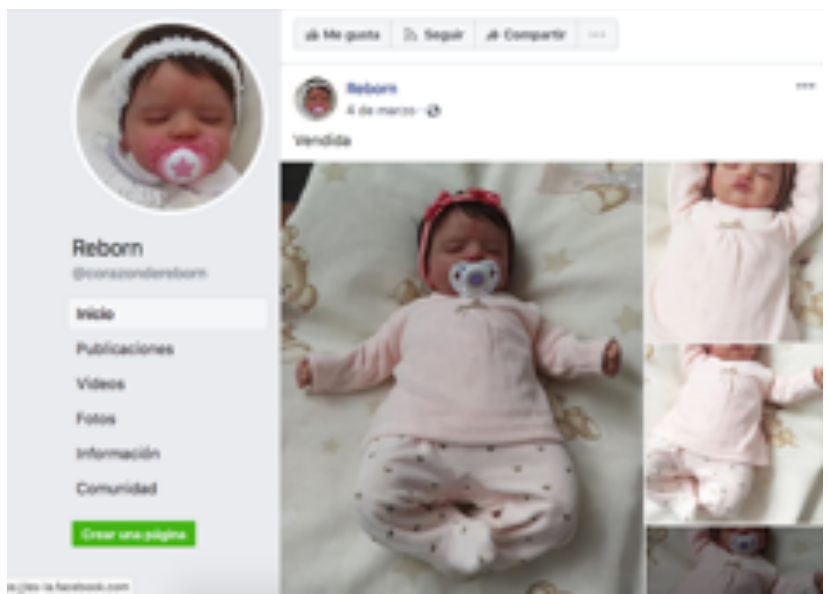

Facebook: @corazondereborn 
Retomando la analogía entre el dildo y la muñeca a partir del texto de Preciado:

Si el dildo es disrruptivo no lo es porque permita a la lesbiana entrar en el paraíso del falo, sino porque muestra que la masculinidad está, tanto como la feminidad, sujeta a las tecnologías sociales y políticas de construcción y de control. El dildo es el primer indicador de la plasticidad sexual del cuerpo y de la posible modificación prostética de su contorno. (67)

Así mismo, cabría decir que la muñeca es disruptiva, no porque permita maternar al cuerpo femenino desprovisto de esta posibilidad, sino porque pone en evidencia lo prostético mismo de la maternidad, subrayando la plasticidad de este deseo materno. El amor de madre, un afecto altamente idealizado por la cultura de todos los tiempos, por su papel en la reproducción de la especie, la familia y el cuerpo nacional, encuentra objeto en un artefacto de plástico tecnificado, una mercancía intercambiable, un fetiche; y el efecto de hacerlo notar es también lo que resulta incómodo en Yo y mi muñeca (1937) de Frida Kahlo.

La operación de desestabilizar uno de los términos de la dupla madre/hijo, al sustituir el hijo por la muñeca, pone el acento sobre la dupla misma, sobre la barra (), que es la frontera o el vector que los une y/o los separa: maternidad, amor maternal, deseo de hijo. En ese desplazamiento que he llamado un tránsito de la sangre al plástico, aparece el saber de la mujer que se reconoce y se reafirma como «yo» en el propio goce de lo que le falta.

\section{Referencias}

Agamben, G. (1995). Estancias. Valencia: Pre-Textos.

Assoun, P.-L. (1995). El fetichismo. Buenos Aires: Nueva Visión.

Cróquer, E. (2016). Hacer excepción. Cuando se habla la lengua de un continente oscuro (III). «Yo soy la desintegración...»: la performance de Frida o el teatro de la crueldad. El taco en la brea, 3(3), 19-35.

Girona, N. (2008). Rituales de la verdad. Mujeres y discursos en América Latina. México/París: Ritma 2/ADEHL.

Haraway, D. (1984). Manifiesto Ciborg. El sueño irónico de un lenguaje común para las mujeres en un circuito integrado. https://xenero.webs.uvigo.es/profesorado/beatriz_suarez/ciborg.pdf

Herrera, H. (1994). Frida Kahlo: las pinturas. Ciudad de México: Diana.

Herrera, H. (2004). Frida: una biografía de Frida Kahlo. Barcelona: Planeta.

Pedraza, P. (1998). Máquinas de amar. Secretos del cuerpo artificial. Madrid: Valdemar.

Preciado, P.-B. (2011). Manifiesto contrasexual. Barcelona: Anagrama.

Robles, H. (1998). Viva la vida. https://www.yumpu.com/es/document/view/14741358/

frida-kahlo-viva-la-vida-dramared 